\title{
A case of a laptop learning campus: how do technology choices affect perceptions?
}

\author{
Jennifer Percival ${ }^{\mathrm{a}}$ and Nathan Percival $^{\mathrm{b} *}$ \\ ${ }^{a}$ Faculty of Business and Information Technology, University of Ontario Institute of \\ Technology, Oshawa, Canada; ${ }^{b}$ Faculty of Engineering and Applied Science, University of \\ Ontario Institute of Technology, Oshawa, Canada
}

(Received 14 January 2009; final version received 19 July 2009)

\begin{abstract}
Laptop learning programs have been developed to create ubiquitous online learning environments. Given the infancy of many programs, there is little understanding of aspects of the program are perceived to provide value to faculty and students. This paper focuses on the value proposition (with respect to perceived benefits versus capital investment) for undergraduate students in a mandatory, campus-wide, comprehensive laptop learning program. Results indicate that the perceived value of the laptop for technical programs such as science, engineering, and information technology, and liberal arts programs such as business and criminology, justice, and policy studies are significantly different. This difference results in a clear need to use different laptop learning models for each type of program and that a single campus-wide model will likely prove unsatisfactory for most students. A need to better communicate the true value of industry-specific software and skills acquisition is also highlighted.
\end{abstract}

Keywords: technology; laptop learning; higher education; student perceptions; classroom software; ownership model

\section{Introduction}

There are an increasing number of universities and colleges implementing laptop learning initiatives in the form of requiring laptops for learning (Brown 2008). These initiatives are motivated by increased market demands for graduates who are technology literate and have strong computer skills (Rola 2002). The laptop programs also allow students to have access to portable labs through simulation software anywhere and at anytime. Although many universities and colleges have initiated laptop learning programs, there is no widely accepted model. Currently, initiatives vary drastically between institutions. Some programs are only for a single program and require the students to come with a laptop with a minimum specification. Other programs apply to entire faculties, programs at a certain year of study, or to entire campuses (Brown, Burg, and Dominick 1998). Figure 1 shows the range of different laptops program that currently exist, from fully student owned programs to a full institutionally provided programs. The majority of schools with laptop learning programs require students to own a laptop (either specifying minimum requirements or requiring it be purchased directly from the institution). According to (Brown 2008), a small

\footnotetext{
*Corresponding author. Email: nathan.percival@uoit.ca
} 


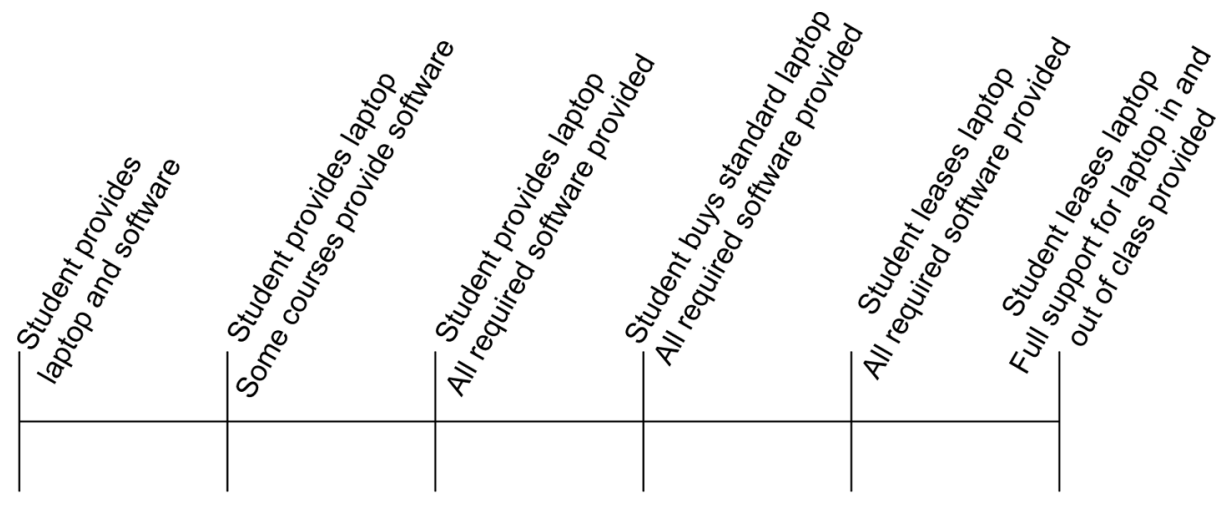

Figure 1. Continuum of laptop learning programs.

number of schools, including the University of Ontario Institute of Technology (UOIT), lease the computers and charge the students a fee for their use.

A number of studies have described the implementation of laptop learning programs at various institutions (Kontos 2001; Elwood, Changchit, and Cutshall 2006). The majority of these studies have been focused on liberal arts applications (MacDougall, Müldner, and Tomek 2004; Elwood, Changchit, and Cutshall 2006) although a few (Thomas et al. 1998; Rickman et al. 2006) have analysed a course or year of study in engineering or computer science. These studies have focused on describing the implementation plans and in explaining faculty and student concerns related to the implementation process. A number of studies have also examined how students use laptops for learning in terms of enumerating the use of applications such as word processors, e-mail, web browsers, and spreadsheets (Finn and Inman 2004). The learning and problem-solving ability of students appears to increase with the integration of laptops into the curriculum. Bohy (2004) found that students who made regular use of laptops in class had higher marks than those that had laptops but used them only intermittently.

If students are not actively engaged in using the laptops during the class then the laptops can become distractions and this inhibits high quality learning (Fried 2008). These results imply that any program where a laptop is optional is likely to have a negative impact on the students' learning, since they cannot be fully integrated into the course to engage all students. Furthermore, to provide an environment where students can be actively engaged requires that all students have access to equivalent types of software and compatible hardware.

Students have expressed a belief that laptops are important for learning but that the laptop learning programs do not offer sufficient value for their investments (Newby 2003). Given the cost of laptops, particularly in lease-based programs, students are concerned about receiving value for their investment. This study will compare and contrast the opinion of students from both liberal arts type programs with opinions of students from technical programs, such as science and engineering, to determine if there is a single model for a laptop program which can efficiently and effectively fulfil the expectations and needs of these diverse populations.

This study aims to identify elements that define students' perceptions of the value of a laptop learning program. We will consider students' perceptions of the value of 
laptop learning programs not only on their use in learning but also on the technical elements such as hardware, software, and support offered as part of the program fee. In particular, this study will not only identify the primary elements of the value proposition but will also compare and contrast the differences between students' perceptions in technically-oriented programs such as engineering or science and liberal art programs such as business and criminology. This will be the first study known to the authors to compare students' perceptions of value between technical and liberal arts programs. It is important to understand the unique needs of each program due to the differences in intensity of software use and high-end computing needs of students in technical fields to support their work. By gaining a deeper understanding into students' perception of value from the laptop learning program, the major obstacles to student satisfaction can be identified, and appropriate changes to the model implemented.

\section{Implementing laptop learning in undergraduate programs}

According to (Brown 2008) as of January 2009 there have been at least 252 universities or colleges worldwide that have, at some time, had a laptop program. Many of these programs are limited to some subset of students such business students, law students or medical students. Based on the data provided, less than $10 \%$ of schools are attempting a program that requires all enrolled students to have a laptop, and most of these programs simply required the students to have a laptop and did not manage a leasing-modelled program. The majority of refresh cycles for leasing programs is two years (Rickman et al. 2006). Rickman et al. (2006) also stated that roughly $70 \%$ of laptop programs are only for specialised programs or levels of study.

Some of the advantages of leasing models include a wider variety of support services, a greater selection of supplied software, reduced compatibility issues, and minimising the total costs to students (Rickman et al. 2006; University of Ontario Institute of Technology 2007). The improvements are a result of the economies of scale that can be found by using campus-wide licensing, entering large volume leasing agreements, and standardising the installation (Thomas et al. 1998). There are some drawbacks to leasing programs as they require additional staff for support services because the university is responsible for repair and maintenance of the technology. Software licensing is also a challenge as software vendors do not always understand these types of programs and negotiations for licensing agreements for leased machines can be complex and time consuming.

\section{Impact of laptop use on student learning}

The results of laptop programs have been mixed (Demb, Erickson, and HawkinsWilding 2004). Hussein et al. (2007) and Digangi et al. (2007) found that faculty and students believe that technology-enhanced laptop programs significantly improve student learning. Digangi et al. (2007) found that $81 \%$ of students thought that laptops were critical for the success at college. Hussein et al. (2007) found that students in Engineering felt that IT-based learning and laptops were valuable tools in the education process. On the other hand, Fried (2008) found that the use of laptops was negatively related to academic success. It should be pointed out that in the Fried (2008) study students were given the option of bringing a laptop whereas 
in the studies such as Hussein et al. (2007) the laptop learning programs were standard and required for all students in the course/program under investigation. When laptops are optional, it is impossible for faculty members to actively integrate them into the curriculum, as they are unsure of how many students will have access to the technology.

Since most of the models do not require standardised software for all students, the ability for faculty to fully integrate the technology into teaching of the curriculum is limited. Many professors have expressed concerns about their ability to adapt to the technology-enhanced environment and to find appropriate software or computerassisted instruction material to support laptop learning initiatives (Platt and Bairnsfather 2000). If students do not have standardised systems, then a significant amount of time is taken in class to deal with software and hardware compatibility issues. The professors must also become experts in a large variety of comparable software in order to address the technical concerns of their students.

Requiring all students to have ubiquitous access to the necessary software and technology to complete labs and assignments allows students greater flexibility and time to explore the design and problem-solving processes of a course. Similarly, being able to access such materials in class allows professors to engage all students through active knowledge construction using technology and moving away from traditional passive lecturing methods (Thomas et al. 1998). Examples of integration into the classroom environment to support active learning include online sharing of student drafts and peer reviews, collaborative online design and workflow programs, interactive polling through clickers or TurningPoint, online simulations, etc. By using laptops to encourage active learning in the classroom, the laptop learning program is changing classroom dynamics by enhancing the scope and depth of learning experience that can occur.

\section{Context for the study: laptop learning at UOIT}

From UOIT's inception in 2003, using technology to enhance teaching has been the mandate of all faculty members hired at the institution. Currently, there are approximately 5100 undergraduate students and 200 graduate students on campus. The majority of the students are from the local community and commute daily from home.

All buildings were designed to include wired connectivity and power connections to every seat in the classroom. A wireless network also services the entire campus. This provides redundant connectivity for every classroom seat. Faculty members and teaching assistants are provided with laptops or tablet computers to integrate the technology into all elements of teaching and learning on campus.

\section{Laptop learning program}

The laptop learning program at UOIT is structured so that all students are required to lease a standard laptop. Every year, all the software required for a student's program is installed on their laptop by the university's IT Services. The base image includes software such as the Microsoft Office Pro suite, web browsers, virus protection software, iTunes, SPSS (a statistical analysis application), and Adobe Acrobat Pro. Each program then supplements the software on the laptop with industry and program specific requirements which may include business 
simulations, Computer Aided Design (CAD) programs, Matlab, Maple, or ChemOffice Ultra. In addition to the laptops, UOIT requires that all courses make use of the university's Learning Management System (LMS). This system is used for course communications such as the distribution of syllabi, slides, discussions, and email. This standardisation allows for a higher level of technology enhancement of learning as all students have access to the leading software used in their industry of study.

Students also have access to an IT support centre for all hardware and general software related questions or repairs. When a laptop repairs requires extensive maintenance, a replacement laptop is loaned to the student. Insurance for damage and theft is also included in the mobile learning fee. The objectives of the laptop learning programs are to provide all students with equal access to technology.

The use of laptop learning devices has increased the expectation of students to have access and interaction with the LMS. The laptop program increases a student's ability to participate in self-directed learning as they are able to access the software applications needed to learn at the time and location that works best with their schedules. The advanced technology skills developed by students provide them with a competitive advantage upon graduation. This has already been demonstrated as the hiring rates for graduates from the Faculty of Education are approximately four times the provincial average.

The laptops are exchanged every two years with students purchasing their laptops at the end of the four year programs for $\$ 1$. The laptop program fee for students is one of the higher fees (Brown 2008) at $\$ 1350$ per year for liberal arts type programs such as education, business, and criminology, and $\$ 1530$ per year for technology heavy programs such as IT, science, and engineering (Brown 2008). Given the large fees associated with the program, there is currently a strong student perception that they are paying too much. This study examines the student perceptions of the value of a laptop program and the impact that the type of program has on the ability of a leased program to be perceived as valuable.

\section{Use of technology in undergraduate teaching}

The integration of technology into undergraduate teaching varies widely based on the type of program being analysed. Some faculties have embraced new technologies and the integration of laptops into the curriculum while others have struggled to find appropriate materials and methods for such integration. The variety of available software and the application of technologies in industry have contributed to the challenges faced by faculty members with the use of the laptops to enhance the student learning experience.

The Faculty of Engineering and Applied Science is an example of how the technically-based programs leverage the laptop program by supplying a large variety of software to its students. In order to support the increasing requirement of employers for advanced skills using design software (Jacobs 1996), every engineering student is provided the opportunity to master technology-based tools focused on engineering design. The faculty receives a number of software applications through Partners for the Advancement of Collaborative Engineering Education (PACE). Through this program, the university has received hardware and software worth over $\$ 680$ million (Partners for the Advancement of Collaborative Engineering Education 2008), the majority of which is software for the laptop program. For the 2008-2009 academic 
year, engineering students will have access to over 75 software applications. These students use software to prepare for labs, complete assignments, and, in some courses, even to do exams. The continuous availability of software allows the instructor to expect students to be familiar with the software and gives the students the ability to become familiar with features beyond those that the courses actually teach.

The students' laptops in the technical-based programs act as portable labs. Through the use of various simulation software packages, students are able to complete experiments that have traditionally been done physically in teaching labs. In addition, some courses provide hardware kits, such as Lego Mindstorms (a robotic, programmable Lego system) that are then able to be programmed anytime anywhere for major course assignments. This allows the student the ability to become more familiar with the intricacies of the systems as they have continuous access to the hardware and software that they need.

In contrast to Engineering, the Faculty of Criminology, Justice and Policy Studies provides a limited amount of software. The students are provided with the base image. In addition, a few upper year courses use the software application NVivo for qualitative research. The majority of the uses of the laptop are therefore word processing, presentations, and as a statistical calculator. The nature of the programs does not provide any significant opportunity to make further use of advanced technical software.

\section{Methodology}

In order to determine how students perceived the value of the laptop learning program, an online survey was created based on input from students, faculty members, and IT Services. The administration of an online survey allowed students to complete the survey at their leisure. Both open ended and Likert scale questions were asked that related to all areas of the laptop learning program including the perceived value of software, hardware, help desk support, insurance coverage, use of technology in the classroom, and printing services. A selection of questions from the survey is included as Appendix 1. The participants were also asked to discuss their views of laptop control/lock-down during classes as well as in-class distractions from the laptops.

Students and faculty members from across the campus were asked to complete the survey through posters, fliers, classroom presentations, posting in the LMS, and the creation of a Facebook group. This resulted in 763 student participants completing the study (15\% of the UOIT population) with significant representation from all years of study (Year 1: 233, Year 2: 213, Year 3: 159, Year 4: 136 and Year 5: 22) and faculties on campus (refer to Table 1). There were 325 female and 438 male survey

Table 1. Response distribution by faculty.

\begin{tabular}{lcc}
\hline Faculty & Number of responses & Percentage of Students \\
\hline Business and Information Technology & 269 & 19.7 \\
Criminology and Justice & 81 & 11.5 \\
Education & 55 & 21.2 \\
Energy Systems and Nuclear Science & 44 & 19.4 \\
Engineering and Applied Science & 117 & 13.5 \\
Health Science & 106 & 12.0 \\
Science & 91 & 17.8 \\
\hline
\end{tabular}


participants. Student ages ranged from 18 to 24 (age 18: 129 , age 19: 161, age 20: 125, age 21: 140, age 22: 76, age 23: 45, age 24: 87).

\section{Results}

\section{Students' perceptions of laptop learning}

When rating the value of the laptop learning program, $74 \%$ of students rated it as significant or very significant. The lowest levels of satisfaction with the program were found in the Faculty of Education and the Faculty of Criminology, Justice, and Policy Studies. The laptop learning program was an influencing factor for $59 \%$ of students when they were choosing which university they wished to attend with the largest impact in technical programs such as engineering and IT. Students also view the laptop learning program as an important part of their educational experience with over $76 \%$ of students stating this program was important or very important to their learning. As can be seen in Figure 2, the percentage of students who perceived the laptop as very important is significantly higher for engineering and IT programs that in program in the liberal arts such as criminology and justice.

While the students were very positive about the program overall, there were some aspects of the program that were not perceived as valuable or satisfactory. Only $65 \%$ of students felt that their professors were at least fair in their use of the laptops for teaching. Students were concerned that the professors were not making use of the laptops during class. Among the comments were that professors simply usied the laptops for PowerPoint presentations during class and this limited usage is a major source of disappointment.

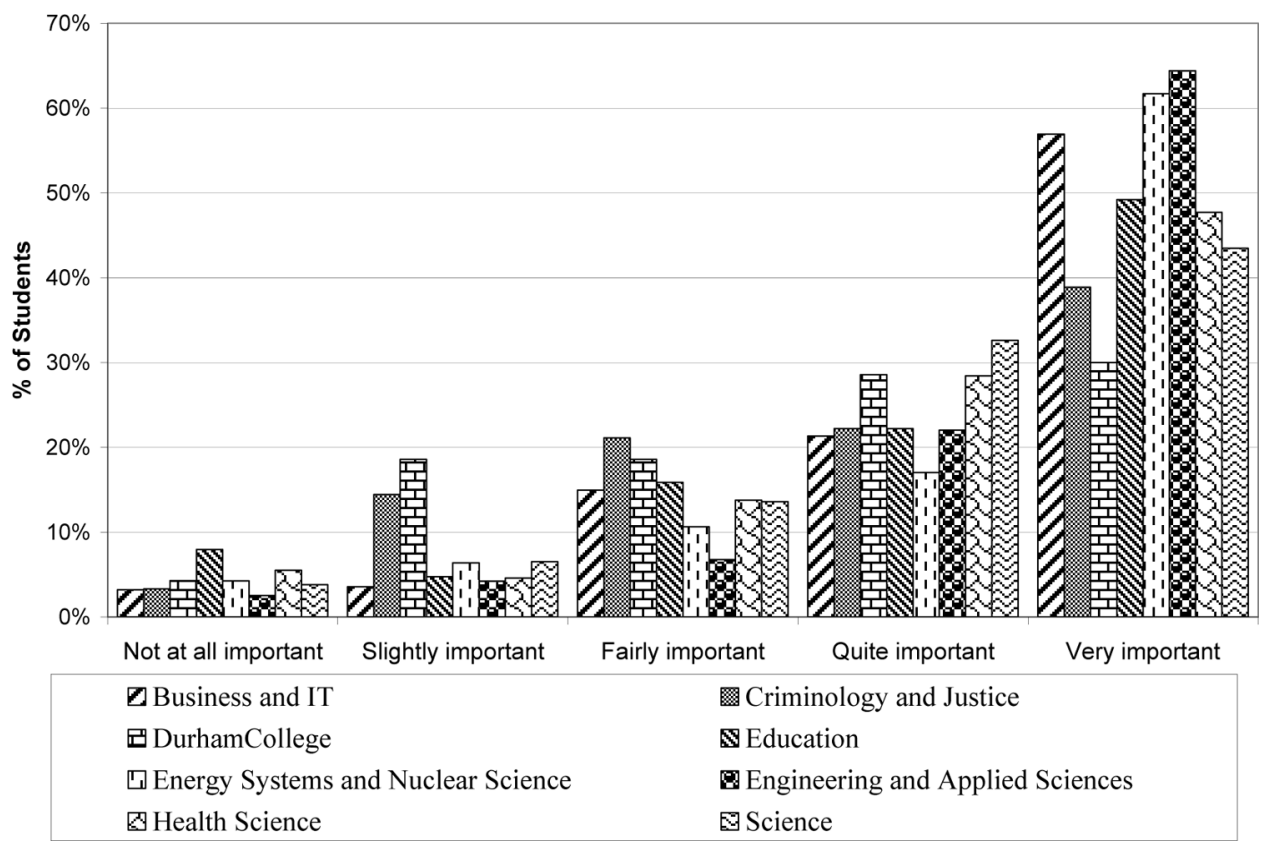

Figure 2. Perceived value by faculty. 
While $70 \%$ of faculty felt that students are distracted by the technology during class, more than $75 \%$ of students did not mind other students using their computers for non-class purposes during class. Student commented that they are being required to pay for the laptops, they should have the right to use them when they want to. "Students have paid their money (tuition \& laptop) and it is their choice how they utilise their investment. It doesn't bother me." (3rd year student.)

In addition to concerns about the professors' use of the laptops, there was an even less positive response about the use of the laptops by teaching assistants (TAs). In the survey, TAs use of technology was rated fair or less by $67 \%$ of students. The lowest occurrence of satisfaction was in the liberal arts programs where TAs typically used the laptops only for marking or email. Another issue, particularly in the technical programs is that since there were no or very few graduate students coming from the universities undergraduates, TAs were hired from the general academic and professional community. This meant that the majority of TAs were not familiar with the vast array of software used in the programs; in most cases, the undergraduate students in second year have more experience using the technology than the TAs. This problem is especially pronounced in the third and fourth year technical courses as there is a need for TAs with advanced knowledge of software that the majority of graduate students will simply not have.

Another major area of concern was the reliability of the LMS. The LMS reliability was important or very important to more than $85 \%$ of students. The LMS is often used as the primary method of communication with professors, TAs, and peers outside the classroom. In addition, most courses use the LMS to provide assignment, laboratory instructions, lecture slides, recordings, and supplementary reading material. Students often simply assume it will be there when they need it, 24/7.

The survey shows that students do not have an accurate understanding of the value of the software being provided. More than 53\% felt indifferent about the value of the software, or that the software was of little or no value. Students commented that they would rather buy the required software themselves or simply download it 'free' from the internet. Many applications that are used in technical classes, such as Matlab, do not have an open source equivalent. In these cases, the students consider any software they can download as free even if they are actually making illegal use of the software. The perceived value of the software provided to the engineering student was lower than average. The estimated annual value for the software on each engineering student laptop exceeds US\$500,000. In contrast, liberal arts students in the criminology and justice program had an even lower opinion of the value of the software with more than $73 \%$ having an opinion of indifferent or less when asked about the value of the software provided (Figure 3 ). These students are receiving little more than the base image and statistical analysis software.

A survey in March 2008 for Symantec (Anon. 2008) showed millennial (those born after 1980) workers are more than twice as likely to use whatever software they want regardless of what they are provided with. In general the survey documented that millennial workers have very different attitudes towards technology compared to older workers (Kapuria 2008). This shift is also being felt in universities where technology resources are provided. All participants in this survey were born after 1983 and over $86 \%$ of students responded that they should not be limited to using only academic resources while on the campus network. The students expressed that what they used the network for was not anyone else's business and that anything that interfered with this was a violation of their rights. 


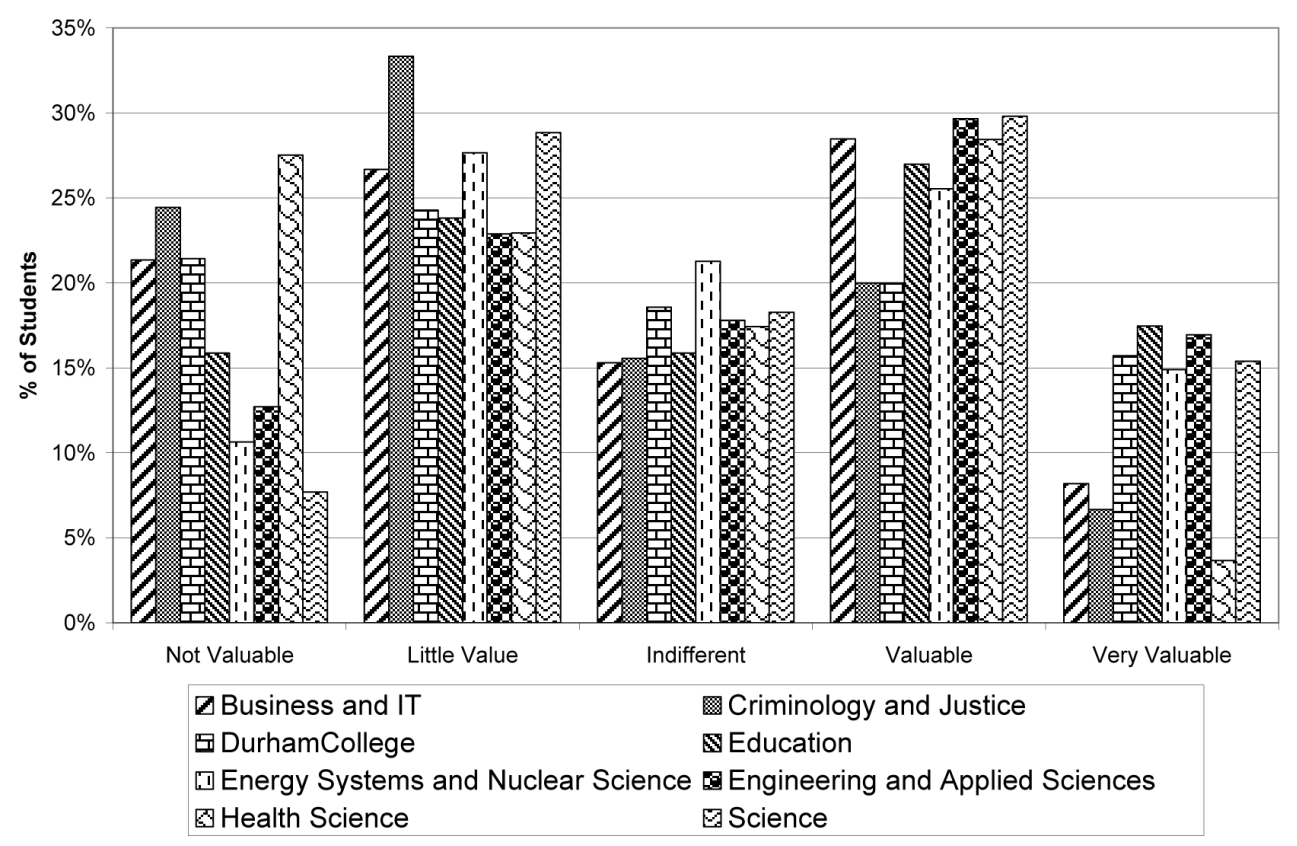

Figure 3. Perceived value of software.

Students from all faculties commented, when asked, that for the money they are paying they could buy a better laptop themselves. They will sometimes allocate a small amount of money for the software but do not consider the infrastructure that supports the use of the laptop as part of the value proposition of the program. Other costs not considered by the students are the annual re-imaging process, compatibility testing to ensure the integration of all software, and the provision of a helpdesk for all problems related to the laptops.

\section{Students' perceptions of obstacles limiting the value of laptop learning}

A major challenge to the laptop learning program is demonstrating to students that the program is worth the required investment. A number of different factors impact the perceived value of the program. For students in the technical programs, the performance of the computers is a major concern due to the demands of the software they use. This is in contrast to laptop programs implemented in liberal arts programs which place minimal demands on the machines. Engineering and science students at UOIT place significant demands on the laptops they are provided. Applications such as Siemens NX 5 and Adobe Creative Suite place significant demands on the laptop's video system. The video adapters in these computers are some of the best adapters commonly available for laptops but only meet the minimum specification for this type of application. Other applications used in the technical programs such as Matlab and (NAsa STRuctural Analysis) NASTRAN programs require a high processor speed and a large amount of memory. Laptop hardware limits the ability to get faster memory or faster processors due to physical and heat dissipation constraints. As a result of these demands, the majority of engineering and science 
students experience three or more performance issues each week while students in liberal arts and business programs experience less than 2.5 on average. Students in engineering and science programs were $31 \%$ more likely to experience a system crash than students in liberal arts programs. The differences between the engineering and science applications and the liberal arts applications challenges laptop learning programs to find a balance between performance and cost. While the number of performance issues could be reduced by providing machine with more memory and faster processors, the increase in cost to the students would be significant and would not necessarily improve the perceived value of the program. In addition, while the updating of computers every 2 years for engineering and science programs is reasonable, liberal arts programs do not need the same level of power and could likely replace machines as infrequently as every 4 years. This difference means that attempts to provide a standard refresh rate for all students is not optimal and results in a dissatisfaction for both groups when the equipment selected attempts to provide a standard machine that is a compromise between the needs of all the groups on the campus.

Another obstacle that limits the perceived value of the laptop learning program is hardware and software reliability. More than $78 \%$ of engineering students experience at least one application crash each week. Overall, engineering and science students experience $20 \%$ more crashes per week than students in business and liberal arts programs. This is despite the integration testing completed by IT Services on the machines prior to deployment. The challenge is that the students are given full control of the laptop and are able to install any application. When surveyed, 95\% of students stated that they want the ability to install applications on their machines. Students take advantage of this access by installing a variety of applications that have not been compatibility tested with the required software.

Battery reliability has also proven to be an obstacle to the student perception of value of the laptop learning program. Thirty nine percent have had issues with the reliability of the batteries in the last year. Most of these issues (more than 90\%) were machines in their second year of use. It appears that the ways that students use the laptops wear out the batteries faster than the traditional business user. This issue needs further investigation but it is believed that the usage patterns of students are significantly different than those of typical laptop users and that the batteries are not currently able to maintain charge levels as well because of the difference in usage and charging patterns.

A final area that seems to have a significant impact on all students' perception of value of the laptop learning program is the actual use of the software in their educational experience. Faculty members routinely require the use of technology for completing assignments but are have not integrated technology as well into their classroom teaching. Some faculty members' only use of technology is the use of PowerPoint during lectures. To the students this is an expected standard and not an additional benefit. Students want to make actual use of their laptop during class through interaction or try something hands-on during the lecture. This issue is not a technical issue but rather one that requires leadership and support from university administration to ensure that faculty have clearly outlined expectation of what instructing in the laptop learning program means as well as constructive feedback on how they can be improved. The expectation of the students to always use their laptop in class may or may not be reasonable but this is beyond the scope of the data collected. 


\section{Recommendations for laptop learning program}

Based on this study, students need to be educated about how the laptop learning program is more than just the physical laptop. In the case of leased programs, the software provided with the machine, technical infrastructure, and support services for the student are also covered by the laptop program fees. The software provided as part of the program is a significant contributor towards the programs perceived value. This is especially true for technical programs where the value of the software provided has a commercial price many times larger than the cost of the actual laptop.

Laptop learning programs need not only to communicate the general benefits of the program to all students but also provide faculty (and possibly program) specific details of the actual value to those students. The details of the value of the software provided to an engineering student will allow the student to better understand what they are getting for their fees, which are different from a liberal arts student's value proposition. This will encourage students to place more value on the software and support services when they consider the value of the program.

Another way that the laptop learning program can increase its perceived value is to increase the use of the laptop in the student learning experience. To accomplish this, more support and incentives need to be provided to faculty members in order to get the technology fully integrated into both the curriculum and into the teaching practices. This integration would allow students to make more use of the technology on a daily basis helping improve their belief that the laptop learning program is valuable to their education.

Laptop learning programs must be designed based on the type of program that they are supporting. Liberal arts and business programs generally use a very limited set of software that are either free or relatively low cost. In addition, they do not change significantly over the four years of a typical degree. In comparison, technically-based programs such as engineering, science, and information technology tend to use a much large set of applications. These specialised applications tend to be much more expensive and are often updated annually. In addition to the cost, many applications require much more power and advanced technology to operate correctly. Because of the highly complex needs of technically-oriented programs, a school-managed program is the best or only way for a laptop program to completely support the integration of technology into the curriculum of technology programs. Liberal arts programs on the other hand can be operated successfully with a student purchase program. In addition, the use of a standard laptop to support both types of programs will likely result in a far too expensive laptop being provided to liberal arts program and a less than optimal product for technical programs.

Finally, the model of using graduate students as TAs for laptops program needs to be reviewed. Traditionally the knowledge and skills of a graduate student in a specific field were sufficient to provide a good level of support to undergraduate students. In a laptop-learning environment, knowledge of a specific field is simply a starting point. The graduate students need to be completely competent with the software applications being used to support the students.

\section{Conclusion and future research}

The use of a lease model for a laptop learning program provides a significant amount of value to students but unfortunately this is challenging to clearly communicate. This lack of understanding by students needs to be overcome through better marketing of 
the value of the program, better integration of the technology into all aspects of the students educational experience, and increased reliability of the laptop hardware or service levels. To better understand the differences in value of a laptop learning program to students, further studies into how students make use of a laptop need to be conducted. Even without this research it appears that a single model for a laptop learning program will be ineffective as there are significant difference in needs between technical and liberal arts types of programs.

Another major student concern is the lack of integration of the laptops into the curriculum by the instructors. Research needs to be conducted to find appropriate uses for laptops in the classroom. Instructors need to be provided with professional development opportunities and resources to support an increased use of technology in the classroom. In addition, the use of technology in teaching must form a component of the feedback and course evaluations provided to the instructors. Further investigation also needs to be undertaken to determine how the perceptions of learning compare to actual learning outcomes. Fried (2008) carried out research into the actual results versus perception but did so in a class where the use of a laptop was optional and hence not integrated into the classroom experience.

The impact of the program on graduating students' ability to find quality employment and provide immediate assistance to their employers is not yet fully understood. A follow up study needs to be conducted with these students and future graduates in order to determine if the skills they acquired through the laptop learning program provided them with a benefit as they entered the workforce. In addition the perceptions of employers regarding students who graduated from the laptop learning program need to be studied to better understand the complete impact of integrating technology into learning.

\section{Acknowledgments}

The authors thank Capstone team 1: Erica Walker, Michael Whibley, Shaun Fitzsimmons, Daniel Noble, William Tsatskas, Stephen Tsatskas, and Shawn Barrans for their assistance in the collection of survey responses and initial review of the results.

\section{References}

Anon. 2008. Symantec Millennials Survey Key Message 3/13/08. http://www.govexec.com/ pdfs/032008b1.pdf.

Bohy, James S. 2004. A new twist on the open vs. closed lab debate: Is there an advantage to being a laptop campus? Proceeding of the Midwest Instruction and Computing Symposium (April). http://www.micsymposium.org/mics_2004/Bohy2.pdf.

Brown, David G., Jennifer J. Burg, and Jay L. Dominick. 1998. A strategic plan for ubiquitous laptop computing. Communications of the ACM 41, no. 1: 26-35.

Brown, Ray. 2008. Colleges with laptop or notebook computer requirements. http:// www2.westminster-mo.edu/wc_users/homepages/staff/brownr/NoteBookList.html.

Demb, Ada, Darlene Erickson, and Shane Hawkins-Wilding. 2004. The laptop alternative: Student reactions and strategic implications. Computers \& Education 43, no. 4: 384-401.

Digangi, Samuel, Zeynep Kilic, Chong Yu Ho, Angel Jannasch-Pennell, Lori Long, Chang Kim, Victoria Stay, and Seok Kang. 2007. One to one computing in higher education: A survey of technology practices and needs. Association for the Advancedment of Computing in Education Journal 15, no. 4: 367-87.

Elwood, Susan, Chuleeporn Changchit, and Robert Cutshall. 2006. Investigating students' perceptions on laptop initiative in higher education: An extension of the technology acceptance model. Campus-Wide Information Systems 23, no. 5: 336-49. 
Finn, Seth, and John G. Inman. 2004. Digital unity and digital divide: Surveying alumni to study effect of a campus laptop initiative. Journal of Research on Technology in Education 36, no. 3: 297-317.

Fried, Carrie B. 2008. In-class laptop use and its effects on student learning. Computers \& Education 50, no. 3: 906-14.

Hussein, M.I., S. Al-Muhtaseb, K. El-Sawy, M. Haggag, and T. Shahin. 2007. Evaluation of IT-based active learning project at the UAE university: College of engineering case study. Emirates Journal for Engineering Research 12, no. 1: 37-42.

Jacobs, H.R. 1996. The utilization of a mobile computing environment in undergraduate education. Paper presented at Frontiers in Education Conference, 26th Annual Conference, November 6-9, in Salt Lake City, Utah, USA, no. 2: 656-8.

Kapuria, Samir. 2008. Millennial workforce: IT risk or benefit? https://forums.symantec.com/ syment/blog/article?message.uid=310250.

Kontos, George. 2001. The laptop university: A faculty perspective. Educational Technology Review 9, no. 1: 1-16.

MacDougall, Glenn, Tomasz Müldner, and Ivan Tomek. 2004. Acadia advantage computerizing a campus. Proceedings of world conference on educational multimedia, hypermedia and telecommunications: 41-6.

Newby, G.B. 2003. Student laptop ownership requirement and centralization of information technology services at a large public university. https://www.infosci-journals.com/downloads/teaching/IT5666.pdf.

Partners for the Advancement of Collaborative Engineering Education. 2008. UOIT receives $\$ 680$ millions in goods. http://www.pacepartners.org/files_pub/press_2008-03-30.pdf.

Platt, M.W., and L. Bairnsfather. 2000. Compulsory computer purchase in a traditional medical school curriculum. Teaching and Learning in Medicine 11, no. 4: 202-6.

Rickman, J., Miller, M., Verbick, T., and K. Todd. 2006. Notebook universities do not have to be expensive. Proceedings of the 34th Annual ACM SIGUCCS Conference on User Services: $333-8$.

Rola, M. 2002. Building IT into lesson plans. Computing Canada 28, no. 22: 28.

Thomas, S. J., Nishida, T., Laxer, C., and H. Sherlock. 1998. The impact of campus-wide portable computing on computer science education. Annual joint conference integrating technology into computer science education: Working group reports of the 3rd annual SIGCSE/SIGCUE ITiCSE conference on integrating technology into computer science education: $35-40$.

University of Ontario Institute of Technology. 2007. 2007-2008 Student value proposition for mobile program. http://its.dc-uoit.ca/mobile/pdf/ValueProp2007-08.pdf. 


\section{Appendix}

A selection of questions from the survey:

- How comfortable were you with technology before you started at this campus?

- Do you have a computer 'at home' other than your UOIT/DC laptop?

- Do you mind that students are using laptops for non-academic purposes in class?

o If yes, why?

- Please rate how much value the laptop provides to you.

- Do you feel the software provides value for the investment?

- Do you feel the service/replacement program provides value for your investment?

- If you had a choice, would you want to lease from the school or purchase a standard laptop?

- How much do you think is fair to pay for the current laptop program? (per year)

- How many times per week do you run into laptop performance problems?

- (Broken into, System Crash, Application Crash, Printing Error, Hardware Error, Battery Problems, Screen Problems \& Other)

- How important is the availability/reliability of WebCT for your learning?

- Would you be interested in using open sourced software?

- How would you rate the help desk?

- Have you had to have your laptop hardware repaired?

$\circ$ If yes, please rate your satisfaction with the service

- How important are laptops to your learning?

- How many of your courses require the use of laptops in lecture?

- How well do Professors use laptops for teaching?

o Please explain your rating:

- Did the laptop program positively influence you coming to UOIT?

- Please explain your answer:

- Did the laptop program meet/exceed your expectations?

- Please explain your answer:

- Rate UOIT faculty competency related to teaching with technology

- Is TAs teaching with the technology tools (hardware and software) provided and did it meet your expectations?

- Is full time faculty teaching with the technology tools (hardware and software) provided and did it meet your expectations 